\title{
Kinetic Evaluation of Influence of Surfactant on Oxidation Reaction of Carboxylic Acid by Molecular $\mathrm{HMnO}_{4}$
}

\author{
VANDANA SHARMA $^{1 *}$, KIRTIYADAV ${ }^{2}$ P.C.CHOYAL ${ }^{3}$ and V.R. CHOUREY ${ }^{4}$ \\ ${ }^{1}$ Government. Holkar Science Autonomous College Indore, India. \\ ${ }^{2}$ Kasturba Gram Rural College, Indore, India. \\ ${ }^{3}$ Government. P.G. College, Dhar, India. \\ ${ }^{4}$ Government. Holkar Science Autonomous College Indore, India. \\ *Corresponding author E-mail: vandana203@gmail.com
}

http://dx.doi.org/10.13005/ojc/330662

(Received: May 04, 2017; Accepted: May 30, 2017)

\begin{abstract}
Surfactant catalyzed oxidation of $n$-butyric acid has been carried out for kinetic and mechanistic investigations in sulphuric acid medium by molecular $\mathrm{HMnO}_{4}$ species. Reaction has also been observed in absence of surfactant. The substrate oxidised in two steps in which first step is slow in comparision to second step which fast one. Micelles of surfactant work as positive catalyst. Substrate and oxidant both follows first order kinetics. Different hypotheses have been applied related to the acidity function to arrive the correct reaction mechanism. Number of moles between substrate and oxidant has also been determined. Temperature variation parameters presented in terms of activation parameters, those are found in prescribed limit. Mechanism for reaction has been suggest on the basis of parameters observed.
\end{abstract}

Keywords: Kinetics, Micelles surfactant, Oxidation, Lauryl sulphate (NaLS)

Acidic permanganate ion.

\section{INTRODUCTION}

Now a day's surfactant has been involved in solution kinetics due to their catalytic efficiency at Pre CMC level. Monomers of surfactant form longer aggregates those are known as micelles ${ }^{1-7}$. In present work an anionic surfactant i.e. sodium lauryl sulphate is used as miceller catalyst. The oxidation kinetics of carboxylic acids has become one of the very interesting subject of investigation and have been examined by number of workers. Since little work has been reported on the oxidation of carboxylic acid by $\mathrm{HMnO}_{4}$ species in presence of micelles as catalyst and about the kinetics and mechanism of many of its important reactions ${ }^{8-12}$ hence the present work has been taken for the research. The oxidation has also been carried out by potassium dichromate from the comparative point of view ${ }^{13-16}$.

The role of permanganate ions as an analytical oxidizing agent in synthetic and analytical works is well known hence it is selected as oxidant in the present investigation. Attempts have also 
been made to elucidate the type of reaction mechanism which is based on the influence of $\mathrm{H}^{+}$ ion on the rate of oxidation reaction. The ZuckerHammett, Bunnett and Bunnett-Olsen hypotheses were applied to know the role of water molecule in the reaction mechanism.

\section{MATERIALS AND METHOD}

Kinetic studies were performed on Systronic 104 spectrophotometer at $525 \mathrm{~nm}$ i.e. at the absorbance maximum of permanganate at constant temperature and at $420 \mathrm{~nm}$ i.e. at the $\lambda_{\text {max }}$ of dichromate. It was verified that there is no interference from other reagent at these wavelengths. All kinetic measurement was conducted under pseudo first order conditions where the substrate was maintained in a large excess over the permanganate and dichromate ion concentration.

The standard solutions of n-butyric acid $(\mathrm{BDH})$ and sodium lauryl sulphate $(\mathrm{BDH})$ were prepared in doubly distilled water. $\mathrm{H}_{2} \mathrm{SO}_{4}$ (Analar) was used as a source of hydrogen ion. Permanganate solution was prepared as given by Vogel ${ }^{17}$. Potassium dichromate solution of Analar grade from Rankem was used.

\section{RESULTS}

Dependency of reaction rate on permanganate concentration and potassium dichromate

Dependency of reaction rate on permanganate has been studied by varying is initial concentration at constant concentration of other reactants. It shows that rate constant does not alter with variation in oxidant concentration. The plot of log of optical density i.e. $\log (a-x)$ and time exhibit double stage process each being linear. It confirms first order kinetics with respect to permanganate (Figure-1.1).

The oxidation has also been carried out by potassium dichromate from the comparative point of view. In this case it has been observed that the reaction is single stage process (Figure-1.2).

From the comparative point of view it has been confirmed that oxidation by dichromate is possible at very low concentration of sulphuric acid in comparision to the oxidation by permanganate. It has also been observed that the rate of oxidation by dichromate is comparatively fast than by permanganate.

\section{Study of variation of substrate concentration}

To study the variation of substrate concentration experiments were performed at $308 \mathrm{~K}$ with different initial concentration of substrate, other reactants concentration were kept constant. The rate for both in uncatalyzed and catalyzed reaction was found to increase with the concentration of substrate. Table. 1.

Plot of logarithm of (n-butyric acid) with logarithm of rate constant $\left(\mathrm{k}_{1}\right.$ and $\mathrm{k}_{1}$ ") give straight line (Fig-1.3) approximately of unit gradient in both the stages. These show that the n-butyric acid follows first order kinetics for each stages and plots of $1 / \mathrm{k}_{1}, 1 / \mathrm{k}_{1}$ " against $1 /$ Substrate concentration (i.e. Michaelis-Menten plots) give straight lines (Fig-1.4) passing through the origin for both the first and second stages. These again exhibit the first order dependence of reaction rate on $n$-butyric acid for both the stages. It also confirms that substrate and oxidant are not forms any intermediate complex ${ }^{18}$. However if any complex is formed, its formation constant would be extremely small ${ }^{19}$.

\section{Effect of the variation of the $\left[\mathrm{H}^{ \pm}\right]$concentration}

The reaction was studied at different sulphuric acid concentrations, keeping the constant concentration of $\mathrm{n}$-butyric acid, potassium permanganate and sodium lauryl sulphate. The variation of the $\left[\mathrm{H}^{+}\right]$concentration on the reaction rate has been investigated. The experimental results obtained are presented in Table. 2.

\section{Applicability of Zucker-Hammett, Bunnett and Bunnett-Olsen hypotheses}

Different hypotheses have been applied to investigate the role and activity of $\mathrm{H}^{+}$ion on the oxidation reaction. In order to determine correlation between $\mathrm{H}^{+}$concentration of rate of reaction, the two Zucker-Hammett ${ }^{20}$ plots i.e. the plot of $\left(\log k_{1}\left(k_{1}{ }^{\prime \prime}\right)\right.$ against $\left.-\mathrm{H}_{0}\right)$ and the other plot of $\left(\log \mathrm{k}_{1}\left(\mathrm{k}_{1}\right)\right.$ against $\left.\log \left[\mathrm{H}^{+}\right]\right)$linearly of above plots exhibit the acid catalysed nature of reaction. However, slope values of Zucker-Hammett plot are not unity as required. Deviation from the ideal slope value of unity suggests that the water molecule may be involved in some way in the slowest rate determining step. Since the ideal slope values (i.e. unity) of two 
Zucker-Hammett plots are not obtained hence the Bunnett's plots ${ }^{21}$ i.e. the Bunnett relationships $\left(\log \left[\right.\right.$ rate constant] $\left.+\log \left[\mathrm{H}_{\mathrm{o}}\right]\right)$ against $\log \mathrm{a}_{\mathrm{H} 2 \mathrm{O}}, \log$ ([rate constant] $-\log \left[\mathrm{H}^{+}\right]$) against $\log \mathrm{a}_{\mathrm{H} 2 \mathrm{O}}$ and $\left(\log\right.$ [rate constant] $\left.-\log \left[\mathrm{H}^{+}\right]-\mathrm{H}_{\mathrm{o}}\right)$ against $\log \mathrm{a}_{\mathrm{H} 2 \mathrm{O}}$ have been obtained. In the same way the Bunnett-Olsen plot $^{22}$ i.e. the plot of linear free energy relationship, i.e. (log [rate constant] $+\mathrm{H}_{0}$ ) against $\left(\mathrm{H}_{0}+\log \left[\mathrm{H}^{+}\right]\right)$has also been obtained. As per Bunnett and Bunnett-Olsen empirical observations the reported slope values of these plots confirms that in the $\left[\mathrm{H}^{+}\right]$catalyzed reactions rate determining step involves the $\mathrm{H}_{2} \mathrm{O}$ molecule. The role of the $\mathrm{H}_{2} \mathrm{O}$ molecule is confirmed as proton abstracting agent in the rate determining step. The slope values of two Bunnett plots i.e. $\omega$ and $\omega^{*}$ and of one BunnettOlsen plots ' $\phi$ ' have been reported in the Table. 3 . The values of $-\mathrm{H}_{0}$ and $\mathrm{a}_{\mathrm{H} 2 \mathrm{O}}$ have been taken from Bunnett, Paul and Long ${ }^{23}$ respectively.

\section{NaLS concentration variation}

Effect of variation of concentration sodium lauryl sulphate (NaLS) has been studied keeping the other reactants constant at given constant temperature.

It is clear that the pseudo first order rate constant for the given concentration range of NaLS increases with the increase in lauryl sulphate Concentration (Table. 4). In the present study, it has been suggested that the formation of premicellar aggregates is responsible for the miceller catalysis.

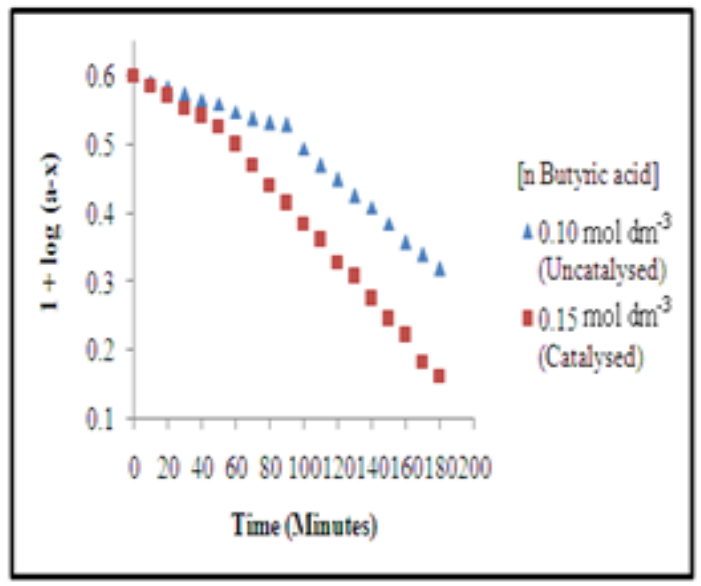

Fig. 1.1.Typical run for the oxidation reaction in sulphuric acid medium $\left(\mathrm{moldm}^{-3}=\right.$ mole lit $\left.^{-1}\right)$
The catalysis by the concentration of micelle which is below their $\mathrm{cmc}$ (i.e. critical micelles concentration) is termed as premiceller catalysis as reported in the literature ${ }^{24-26}$. It has been determined graphically by plotting a Piszkiewicz graph between log $\left[\mathrm{k}_{\text {obs }}-\mathrm{k}_{\mathrm{o}}\right] /\left[\mathrm{k}_{\mathrm{m}}-\mathrm{k}_{\mathrm{obs}}\right]$ and log [NaLS]. Here $k_{o}$ is the velocity constant in absence of NaLS, $k_{\text {obs }}$ is the velocity constant at different NaLS concentration, while $\mathrm{k}_{\mathrm{m}}$ is the maximum velocity constant in presence of NaLS used. The range of variation of NaLS were kept between from $5.0 \times 10^{-4}$ to $9.0 \times 10^{-4} \mathrm{~mol}^{\text {liter }}{ }^{-1}$. Its maximum concentration used is $9.0 \times 10^{-4}$ mole liter $^{-1}$. This is well below the reported $\mathrm{cmc}$ of sodium lauryl sulphate as reported in the literature is $8.1 \times 10^{-3}$ mole liter ${ }^{-1}$ at $298 \mathrm{~K}$. This confirms that the observed phenomenon is a case of premiceller catalysis.

The slope value ' $n$ ' obtained from this graph which is a good straight line for first and second stages are 1.86 and 2.01. These are between the expected value i.e. between 1 to 6 which is for premiceller catalysis. In the case of miceller catalysis this value should be more than 20. This is according to the binding parameters as suggested by Piszkiewicz ${ }^{27}$.

The results have been reported in the table 4 for both the stages. The ' $n$ ' value of positive cooperativity also supports the substrate promoted micellization which is analogous to positive cooperativity in case of enzymatic reactions ${ }^{28-30}$.

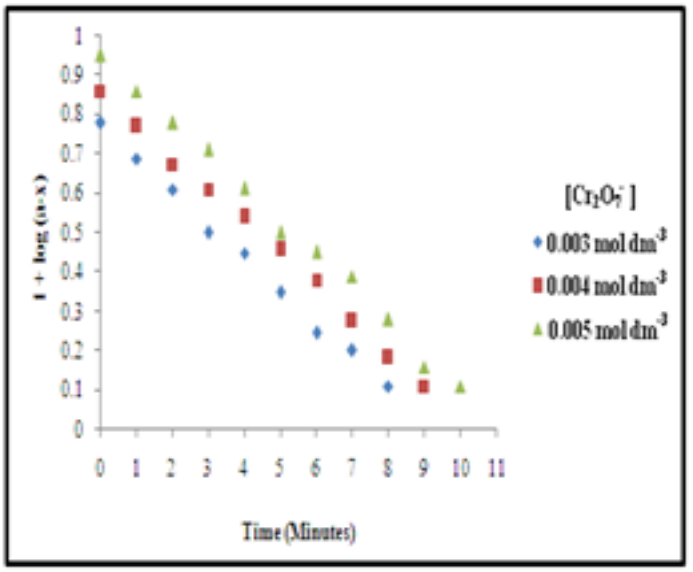

Fig. 1.2: variation of [Dichromate] 


\section{Change in Temperature on reaction}

The reaction was studied at different temperature i.e. $303,308,313$ and $318 \mathrm{~K}$ at the constant concentration of all the reactants. The result has been presented in the Table. 5 .

Different activation parameters like $\Delta \mathrm{E}^{\neq}$, $\Delta \mathrm{H}^{\neq}, \Delta \mathrm{S}^{\neq}, \mathrm{pZ}$ and $\Delta \mathrm{G}^{\neq}$have been evaluated from the temperature variation studies, the various kinetic by their standard equations and reported in the table 6 . The values of $\Delta \mathrm{E}^{\neq}$has also been calculate from the Arrehenius plots ${ }^{31}$ and have been reported in the respective table.

\section{Stoichiometry of reaction}

It was determined by analytical method. This involves the known excess of $\mathrm{KMnO}_{4}$ over the substrate i.e. n-butyric acid kept at room temperature for a sufficiently long time ( $36 \mathrm{~h}$ ). The unreacted permanganate was estimated iodometrically. It has been found that the five mole of substrate consumes one mole of potassium permanganate. The catalyzed reaction is suggested to be proceeds as follows:

$5 \mathrm{CH}_{3} \mathrm{CH}_{2} \mathrm{CH}_{2} \mathrm{COOH}+2 \mathrm{MnO}_{4}^{-}+6 \mathrm{H}^{+} \rightarrow 2 \mathrm{Mn}^{2+}+$ $5 \mathrm{CH}_{3} \mathrm{CH}_{2} \mathrm{CH}_{2} \mathrm{OH}+5 \mathrm{CO}_{2}+3 \mathrm{H}_{2} \mathrm{O}$

Propyl alcohal was identified by spot test method as given by Fige ${ }^{32}$ and Carbon dioxide have been determined by routine test as the end products. The formation of intermediate free radical is confirmed by induced reduction of mercuric chloride. Low value of energy of activation also supports the same.

\section{Mechanism}

On the basis of the results of kinetic measurements facts and discussion the following steps for the oxidation reaction of n-butyric acid in the absence and presence of sodium lauryl sulphate as catalyst has been suggested.

\section{Mechanism and rate law for uncatalyzed oxidation}

The mechanism proceeds with the formation of molecular $\mathrm{HMnO}_{4}$ in sulphuric acid medium

$\mathrm{MnO}_{4}^{-}+\mathrm{H}^{+} \stackrel{\mathrm{X}_{2}}{\rightleftarrows} \mathrm{HMnO}_{4}$ 
Which is more powerful oxidizing species of $\mathrm{MnO}_{4}$ $\mathrm{CH}_{3} \mathrm{CH}_{2} \mathrm{CH}_{2} \mathrm{COOH}+\mathrm{HMnO}_{4}+\mathrm{H}_{2} \mathrm{O} \frac{\ell_{4}}{30 y} \mathrm{CH}_{3} \mathrm{CH}_{2} \mathrm{CH}_{2} \mathrm{COO}^{-}+\mathrm{HMnO}_{4}^{-}+\mathrm{H}_{3} \mathrm{O}^{+}$

Step (2) is rate determining step. The cause of slowness is the involvement of three body collision which is difficult one. All subsequent steps are very fast and not of kinetic importance, are as follows;

$\mathrm{CH}_{3} \mathrm{CH}_{2} \mathrm{CH}_{2} \mathrm{COO} \stackrel{\text { fost }}{\longrightarrow} \mathrm{CH}_{3} \mathrm{CH}_{2} \mathrm{CH}_{2}{ }^{-}+\mathrm{CO}_{2}$

$\mathrm{CH}_{3} \mathrm{CH}_{2} \mathrm{CH}_{2}^{-}+\mathrm{HMnO}_{4} \stackrel{\text { fast }}{\longrightarrow} \mathrm{CH}_{3} \mathrm{CH}_{2} \mathrm{CH}_{2}^{+}+\mathrm{HMnO}_{4}^{-}$

$\mathrm{CH}_{3} \mathrm{CH}_{2} \mathrm{CH}_{2}^{+}+\mathrm{H}_{2} \mathrm{O} \stackrel{\text { fost }}{\longrightarrow} \mathrm{CH}_{3} \mathrm{CH}_{2} \mathrm{CH}_{2} \mathrm{OH}+\mathrm{H}^{+}$

$\mathrm{CH}_{3} \mathrm{CH}_{2} \mathrm{CH}_{2}{ }^{-}+\mathrm{CH}_{3} \mathrm{CH}_{2} \mathrm{CH}_{2}{ }^{-} \stackrel{\text { fast }}{\longrightarrow} \mathrm{C}_{6} \mathrm{H}_{2}$

The above mechanism leads to suggest the rate expression for uncatalyzed reaction; in which the concentration of hydrogen ion and water have been withdrawn from main equation.

$-\frac{\mathrm{d}\left[\mathrm{MnO}_{4}^{-}\right]}{\mathrm{dt}}=\mathrm{K}_{\mathrm{s}}\left[\mathrm{CH}_{3} \mathrm{CH}_{2} \mathrm{CH}_{2} \mathrm{COOH}\right]\left[\mathrm{MnO}_{4}\right]$

Where

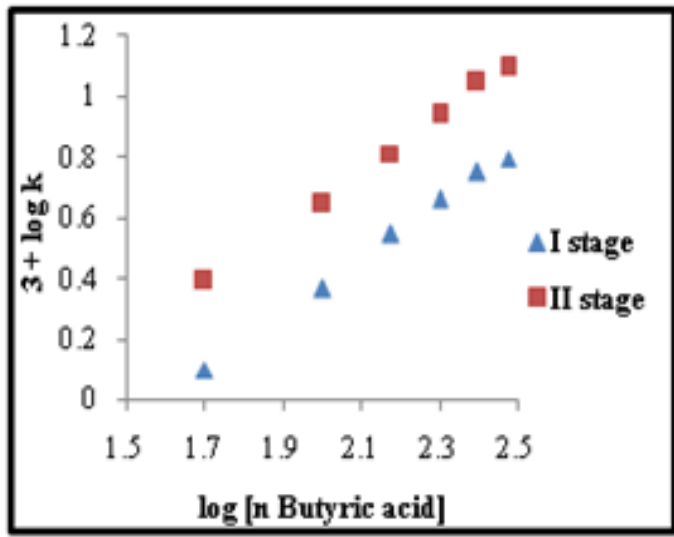

Fig. 1.3. log k against log [Substrate] Catalysed
$\mathrm{K}_{\mathrm{s}}=\frac{\mathrm{K}_{1} \mathrm{~K}_{1} \mathrm{~K}_{2}[\mathrm{H}+]^{2}\left[\mathrm{H}_{2} \mathrm{O}\right]}{\left\{1+K_{2}\left[H^{+}\right]\right\}}$

Mechanism and rate law for catalyzed reaction

The reaction rates have been found substantially increased in presence of anionic sodium lauryl sulphate surfactant. It is assumed that due to the electrostatic interaction between $n$ butyric acid and micelles of surfactant leads the increase in effective concentration which is responsible for the increase in reaction rate. The very low values of number ' $n$ ' of surfactant molecules i.e. below 20 are expected in micelles. The mechanism proposed, therefore involve the substrate-surfactant interaction, with the premiceller catalysis phenomenon as the $\mathrm{n}$, calculated has the value below 20 .

$\mathrm{CH}_{3} \mathrm{CH}_{2} \mathrm{CH}_{2} \mathrm{COOH}+\mathrm{H}^{+} \stackrel{k_{1}}{\rightleftharpoons} \mathrm{CH}_{3} \mathrm{CH}_{2} \mathrm{CH}_{2} \mathrm{COOH}_{2}^{+}$

$\mathrm{MnO}_{4}^{-}+\mathrm{H}^{+} \mathrm{aq} \stackrel{k_{2}}{\rightleftharpoons} \mathrm{HMnO}_{4}$

(Molecular)

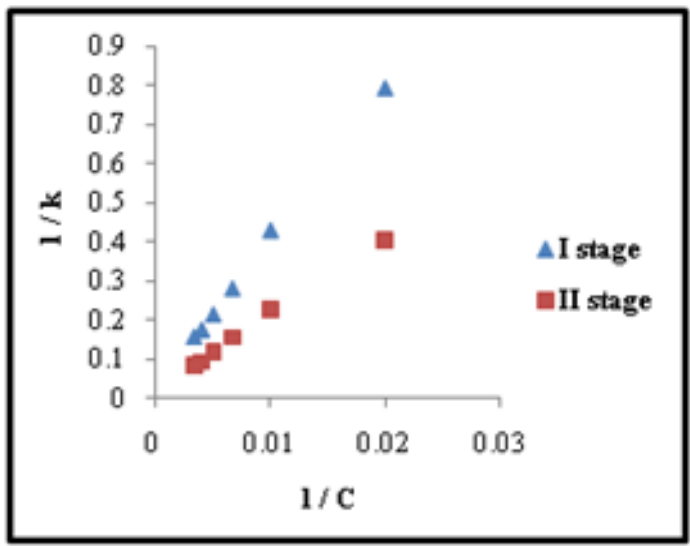

Fig. 1.4. Michaelis Menton plot Catalysed

Table. 2 : Study of change in the $[\mathrm{H}+]$ concentration

[n-butyric acid] $=0.20$ mole lit-1Temperature $=308 \mathrm{~K}$

$[\mathrm{KMnO} 4]=1.0 \times 10^{-3}$ mole lit $^{-1}[\mathrm{NaLS}]=1.0 \times 10^{-4}$ mole lit $^{-1}$

$\left[\mathrm{H}^{+}\right]$mole lit ${ }^{-1} \quad-\mathrm{H}_{0} \quad-\log \mathrm{a}_{\mathrm{H} 2 \mathrm{O}} \quad \mathrm{k}_{1} \times 10^{-3} \mathrm{Min}^{-1} \quad \mathrm{k}_{1}{ }^{\prime \prime} \times 10^{-3} \mathrm{Min}^{-1}$

\begin{tabular}{lllll}
\hline 2.0 & 0.84 & 0.043 & 1.20 & 2.41 \\
2.5 & 1.12 & 0.063 & 1.33 & 3.25 \\
3.0 & 1.38 & 0.085 & 1.63 & 4.75 \\
3.5 & 1.62 & 0.111 & 2.04 & 6.20 \\
4.0 & 1.85 & 0.142 & 2.44 & 8.67 \\
\hline
\end{tabular}


$\mathrm{n}(\mathrm{NaLS}) \rightleftharpoons(\mathrm{NaLS}) \mathrm{n}$ ( $\mathrm{n}$ is below CMC)

$(\mathrm{NaLS})_{n}+\mathrm{CH}_{3} \mathrm{CH}_{2} \mathrm{CH}_{2} \mathrm{COOH}_{2}^{+} \stackrel{\mathrm{H}_{4}}{\longrightarrow}\left(\mathrm{NaLS}_{2}\right) \cdots \mathrm{CH}_{3} \mathrm{CH}_{2} \mathrm{CH}_{2} \mathrm{COOH}_{2}^{+}$ ( $\mathrm{n}$ = below 20) Substrate - Surfactant association (without covalent bonds)

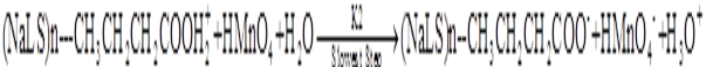

Purely physical premiceller catalysis

$(\mathrm{NaLS})_{n}-\mathrm{CH}_{3} \mathrm{CH}_{2} \mathrm{CH}_{2} \mathrm{COOH}_{2}^{+} \stackrel{\text { Fat }}{\longrightarrow}(\mathrm{NaLS})_{1}-\cdots \mathrm{CH}_{3} \mathrm{CH}_{2} \mathrm{CH}_{2}^{-}+\mathrm{CO}_{2}$

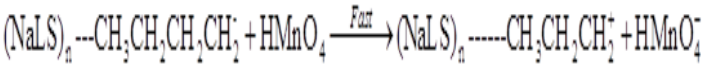

$\mathrm{CH}_{3} \mathrm{CH}_{2} \mathrm{CH}_{2}^{+}+\mathrm{H}_{2} \mathrm{O} \stackrel{\text { Fast }}{\longrightarrow} \mathrm{CH}_{3} \mathrm{CH}_{2} \mathrm{CH}_{2} \mathrm{OH}+\mathrm{H}^{+}$
The following rate law expression may be derived from above discussed steps considering that catalyzed and uncatalyzed reactions proceeds simultaneously.

$-\frac{\mathrm{d}\left[\mathrm{MnO}_{4}^{-}\right]}{\mathrm{dt}}=\frac{\mathrm{K}_{1} \mathrm{~K}_{2} \mathrm{~K}_{1} \mathrm{~K}_{2} \mathrm{~K}_{3}\left[\mathrm{H}_{2} \mathrm{O}\right]\left[\mathrm{CH}_{3} \mathrm{CH}_{2} \mathrm{CH}_{2} \mathrm{COOH}_{2}^{+}\right]\left[\mathrm{MnO}_{4}^{-}\right]}{\left\{1+\mathrm{k}_{2}\left[\mathrm{H}^{+}\right]\right\}}$ $-\frac{\mathrm{d}\left[\mathrm{MnO}_{4}^{-}\right]}{\mathrm{dt}}=\mathrm{K}^{\prime \prime} \quad[\mathrm{NaLS}]_{\mathrm{n}}\left[\mathrm{CH}_{3} \mathrm{CH}_{2} \mathrm{CH}_{2} \mathrm{COOH}_{2}^{+} \cdot\right]\left[\mathrm{MnO}_{4}^{-}\right]$ Here

$\mathrm{K}^{\prime \prime}=\frac{K_{1} K_{2} K_{1} K_{2} K_{3}\left[H^{+}\right]^{2}\left[H_{2} O\right]}{\left\{1+K_{2}\left[H^{+}\right]\right\}}$

Table. 3 : Correlation of reaction rate with $[\mathrm{H}+]$ concentration

[n-butyric acid] $=0.20$ mole lit $^{-1}$ Temperature $=308 \mathrm{~K}$ $\left[\mathrm{KMnO}_{4}\right]=1.0 \times 10^{-3}$ mole lit $^{-1}[\mathrm{NaLS}]=1.0 \times 10-4$ mole lit $^{-1}$

S.No Correlation $\begin{array}{ll}\text { Parameters } & \left.\begin{array}{l}\text { Slope value } \\ \text { I stage }\end{array} \mathrm{H}_{2} \mathrm{SO}_{4} \text { medium }\right)\end{array}$

1. Zucker-Hammett plot

(a) (log Rate constant) against - $\mathrm{HO}$

(b) (log Rate constant) against $\log \left[\mathrm{H}^{+}\right]$

Slope

0.316

0.553

2. Bunnett's plots

(a) (log Rate constant $+\mathrm{H} 0)$ against

Slope

1.23

1.58

(b) (log Rate constant - log $\left.\left[\mathrm{H}^{+}\right]\right)$against

$(\omega)$

$-6.88$

$-4.51$

(b) (log Rate constant - $\left.\log \left[\mathrm{H}^{+}\right]\right)$against

$\left(\omega^{*}\right)$

0.250

2.62

(c) (log Rate constant] - $\left.\log \left[\mathrm{H}^{+}\right]-\mathrm{H} 0\right)$ against

Slope

10.37

12.74

3. Bunnett - Olsen plot (L.F.E.R)

(a) (log Rate constant $+\mathrm{HO})$ against

$(\phi)$

0.972

0.636

Where ' $a$ ' is for absent

Table. 4 : Dependence of rate on NaLS Concentration and Catalytic Constant

[n-butyric acid $]=0.10$ mole lit $^{-1}\left[\mathrm{H}_{2} \mathrm{SO}_{4}\right]=4.0$ mole lit $^{-1}$

$\left[\mathrm{KMnO}_{4}\right]=1.0 \times 10^{-3}$ mole lit $^{-1}$ Temperature $=308 \mathrm{~K}$

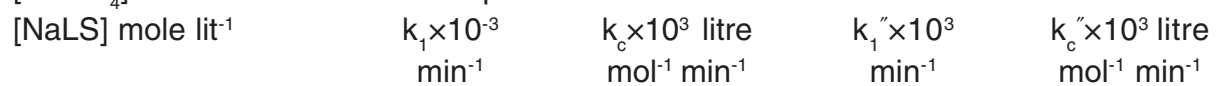

\begin{tabular}{lllll}
\hline Uncatalyzed(Absent) & 2.10 & - & 3.99 & \\
$1.0 \times 10^{-4}$ & 2.32 & 2.20 & 4.41 & 4.20 \\
$2.0 \times 10^{-4}$ & 2.58 & 2.40 & 4.81 & 4.10 \\
$3.0 \times 10^{-4}$ & 2.86 & 2.53 & 5.30 & 4.36 \\
$4.0 \times 10^{-4}$ & 3.04 & 2.35 & 5.70 & 4.27 \\
$5.0 \times 10^{-4}$ & 3.29 & 2.38 & 6.15 & 4.32 \\
$6.0 \times 10^{-4}$ & 3.59 & 2.48 & 6.50 & 4.18
\end{tabular}


Table. 5 : Effect of Temperature variation

\begin{tabular}{|c|c|c|c|c|}
\hline \multicolumn{5}{|c|}{$\begin{array}{l}{[\text { n-butyric acid }]=0.10 \text { mole lit }^{-1}\left[\mathrm{H}_{2} \mathrm{SO}_{4}\right]=4.0 \text { mole lit }^{-1}} \\
{\left[\mathrm{KMnO}_{4}\right]=1.0 \times 10^{-3} \text { mole lit }^{-1} \mathrm{Temperature}^{-}=308 \mathrm{~K}}\end{array}$} \\
\hline \multirow[t]{3}{*}{ Temp.(K) } & \multicolumn{2}{|c|}{ Velocity constant for } & \multirow{2}{*}{\multicolumn{2}{|c|}{$\begin{array}{l}\text { Velocity constant for Catalyzed } \\
\text { NaLS }=1.0 \times 10^{-4} \text { mole } \text { lit }^{-1}\end{array}$}} \\
\hline & Uncatalyzed & $\mathrm{NaLS}=\mathrm{Nil}$ & & \\
\hline & $\mathrm{k}_{1} \times 10^{-3} \mathrm{Min}^{-1}$ & $\mathrm{k}_{1}^{\prime \prime} \times 10^{-3} \mathrm{Min}^{-1}$ & $\mathrm{k}_{1} \times 10^{-3} \mathrm{Min}^{-1}$ & $\mathrm{k}_{1}^{\prime \prime} \times 10^{-3} \mathrm{Min}^{-1}$ \\
\hline 303 & 1.38 & 2.10 & 1.84 & 2.44 \\
\hline 308 & 2.10 & 3.99 & 2.32 & 4.41 \\
\hline 313 & 3.10 & 4.50 & 3.83 & 5.07 \\
\hline 318 & 4.61 & 8.44 & 4.72 & 8.80 \\
\hline \multirow{2}{*}{$\begin{array}{l}\text { Selected } \\
\text { Temp.(K) }\end{array}$} & \multicolumn{2}{|c|}{ Temp. coeff. for Uncatalyzed } & \multicolumn{2}{|c|}{ Temp. coeff. for Catalyzed } \\
\hline & I step & II step & I step & II step \\
\hline $303-313$ & 2.24 & 2.14 & 2.08 & 2.07 \\
\hline $308-318$ & 2.19 & 2.11 & 2.03 & 1.99 \\
\hline
\end{tabular}

Table. 6: Thermodynamic and Activation Parameters (For Uncatalyzed and Catalyzed reaction)

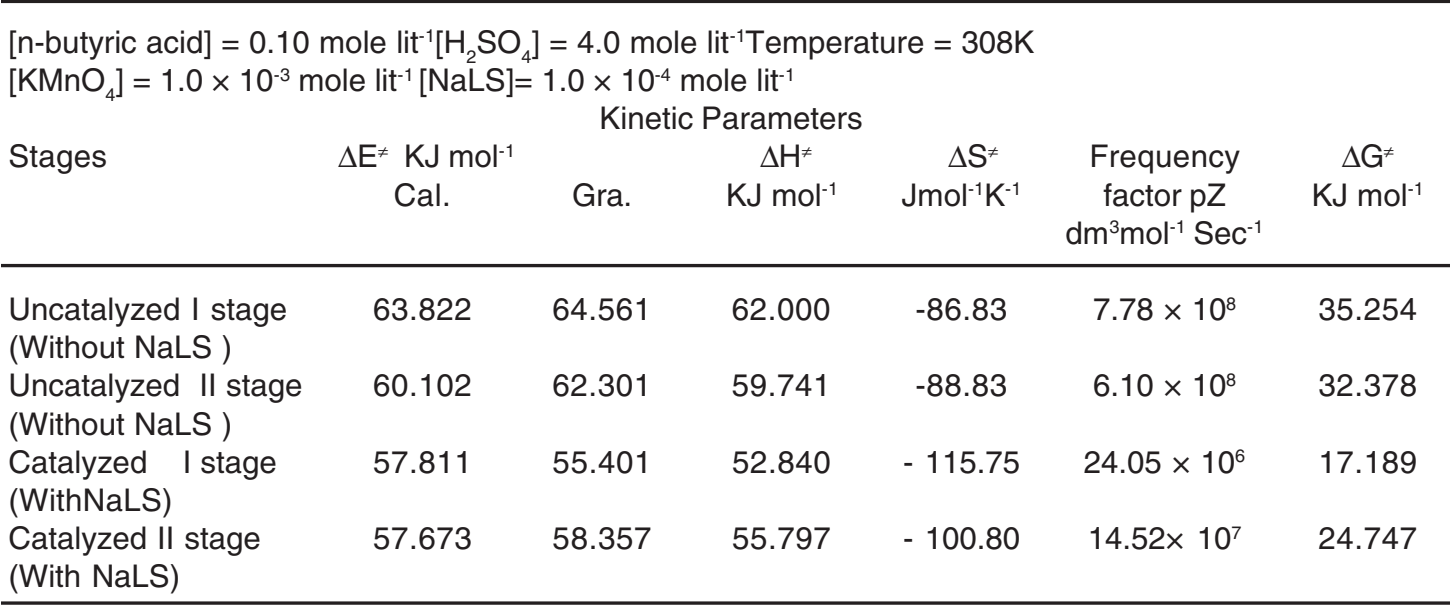

\section{DISCUSSION}

In the studied reaction the order for $n$ butyric acid and molecular permanganate has been found as one i.e. $\mathrm{HMnO}_{4}$ were found one in each case.The role of surfactant is only as premiceller physical catalyst with no covalent bond formation between surfactant - substrate association. Rate law involve the acid concentration term and water molecule. Zucker-Hammett, Bunnett's and Bunnett-
Olsen Hypotheses suggest the involvement of water molecule as a proton abstracting agent in the reaction.

\section{ACKNOWLEDGEMENT}

The author Vandana Sharma is thankful to Dr. Smt. R. Vyas Head Department. of Chemistry Holkar Science College Indore for providing all necessary research facilities.

\section{REFERENCES}

1. Bhagwat,V. W.; Pipada, M.;Tumalagada, S B.; Pare, B. Ind. J. Chem., 2003, 42A, 1644.

2. Kabir-ud-din; Shakeel Iqubal, S. M.; Khan, Z. Ind. J. Chem., 2005, 42, 2455.
3. Prakash, R. J. Ultra Chem., 2010, 6(3), 357.

4. Bende, N.; Chourey, V. R. Res. J. Chem. Environ., 2013, 17(06), 75-87.

5. Sharma, V.; Chourey, V. R. J. Ultra Chem., 
2013, 09(03), 287-302.

6. Sharma, V.; Chourey, V. R. Int. J. Advance Research, 2014, 2(3), 764-772.

7. Sharma, V.; Chourey, V. R. Int. J. Advance Research, 2014, 2(6), 617-625.

8. Vanangnudi, C.; Subbaiyan, M.; Srinivans, S. Asian J. Chem., 2007, 19(04), 71.

9. Hall, L.; Singh, A. C. J. Chem. Educ. 1988, 65,142 .

10. Sharma, A.; Sharma, A. K.; Gupta, K. S. J. Indian Chem. Soc., 2009, 86, 649.

11. Wiberg, K. B.; Steward, R. J. Am. Chem. Soc., 1956, 78, 1214.

12. Bhale, V. M.; Mohammad, S.; Bhagwat, W. V.; Bafna, S. C. J. Sci. Ind. Research (India), 1953, 1954, 12,13, 521, Chem. Abst., 48, 5620.

13. Khandual, N. C.; Satpathy, K. K.; Nayak, P. L. Indian J. Chem., 1973,11, 770-772.

14. Venkatraman R.; Rao S. B. Indian J. Chem., 1972, 10, 165-167.

15. Khan Z.; Kabiruddin Indian J. Chem., 2000, 39, 552.

16. Wankhade, C. B.; Khodakar, S. N.; Patel, N. T. Asian J. Chem., 2006, 18(4), 2538.

17. Vogel, A. I. "A text book of quantitative Inorganic analysis" Longman Green,
London, 1964, 282.

18. Mehrotra, R. N. J. Chem. Soc., 1968, 1123.

19. Sankhla, P. S.; Mehrotra, R. N. Indian J. Chem., 1972, 10, 1081, 2077.

20. Zucker, L.; Hammett, L. P. J. Am. Chem. Soc., 1939, 61, 2791.

21. Bunnett, J. F. J. Am. Chem. Soc., 1961, 83, 4968.

22. Bunnett, J. F.; Olsen, F. P. Can. J. Chem., 1899, 1917, 1966, 44.

23. Paul, M. A.; Long, F. A. Chem. Rev., 1957,57,1.

24. Bruice, J. C.; Katzhendler, J.; Fedar, L. J. Am. Chem. Soc., 1968, 90,133.

25. Sarasan, G. Asian J. Chem., 2003, 15(1), 133.

26. Prakash, R.; Agrawal, S. J. Ultra Chem., 2012, 8(3), 309.

27. Piszkiewicz, D. J. Am. Chem. Soc., 1977, 99, 1550.

28. Raghavan. Ind. J. Chem., 1980, 19(A), 322-324.

29. Behara, G. B.; Mishra, S. S.; Samantaray Ind. J. Chem., 1982, 21(A),1063-1065.

30. Pare, B.; Kaur, P.; Bhagwat, V. W.; fogliani, C. J. Korean Chem. Soc., 2004, 48,195.

31. Laidler, K. J. "Chemical Kinetics", Third Edn. Tata Mc. Graw Hill, Bombay, 2004, 39.

32. Fiegl, F. "spot test in Organic Analysis", 1955, 174. 